\title{
Metode Klasifikasi Mutu Greenbean Kopi Arabika Lanang Dan Biasa Menggunakan K-Nearest Neighbor Berdasarkan Bentuk
}

\author{
Dedy Ikhsan ${ }^{1)}$, Ema Utami $^{2}$, Ferry Wahyu Wibowo ${ }^{3)}$ \\ 1, 2 ) Magister Teknik Informatika, Universitas Amikom Yogyakarta \\ ${ }^{3)}$ Informatika, Universitas Amikom Yogyakarta \\ 1) dedyikhsan22@gmail.com, ${ }^{2)}$ emma@nrar.net, ${ }^{3)}$ ferry.w@ amikom.ac.id
}

\begin{abstract}
During this time, the Greenbean coffee sorting process is still done manually which still has many shortcomings. Manually, this result is classified in inappropriate and inconsistent classification results due to human negligence. Grading in the processing and marketing sectors is important. Inappropriate grading opposes farmers simply because Lanang and ordinary Arabica coffee are the same. Hence, we need a consistent classification system. This research uses image processing to recognize Greenbean Arabica coffee. K-NN (K-Nearest Neighbor) method is used for a quality classification. This research will classify Arabica Greenbean coffee into 4 quality classes, namely intact Lanang Arabica, broken Lanang Arabica, intact ordinary Arabica, and ordinary broken Arabica. The search of trial process shows that $K-N N$ classification feature is able to recognize Arabica coffee Greenbean into 4 classes with an accuracy value of $63.5 \%$, very good at recognizing $90 \%$ of regular Arabica intact and $97 \%$ of whole Arabica intact. However, it is still weak in recognizing broken coffee Greenbean based on its type. The area feature is better in recognizing Arabica coffee Greenbean based on 4 classes with an accuracy of 69.8\%. This research obtains 120 datasets from 80 tested data trains and 40 tested random data.
\end{abstract}

Keywords: Digital image processing, $k$-nearest neighbor, classification of Greenbean Arabica

\section{PENDAHULUAN}

Dalam komoditi kopi arabika terdapat dua macam jenis greenbean kopi yaitu kopi arabika lanang (monokotil) dan biasa (dikotil). Dalam rangka meningkatkan daya saing tersebut maka greenbean kopi arabika yang dihasilkan harus dapat memenuhi standar pasar dalam negeri maupun pasar internasional dan diterima secara luas oleh konsumen. Greenbean kopi arabika sudah terdaftar dalam Standar Nasional Indonesia dengan nomor SNI 01-2907:2008.

Pengolahan citra atau Image Processing adalah kegiatan memperbaiki kualitas citra agar mudah diinterpretasi oleh manusia/mesin (komputer). Masukannya adalah citra dan keluarannya juga citra tapi dengan kualitas lebih baik dari pada citra masukan, misal citra warnanya kurang tajam, kabur (blurring), mengandung noise (misal bintik-bintik putih), sehingga perlu ada pemrosesan untuk memperbaiki citra karena menjadi sulit diinterpretasikan karena informasi yang disampaikan menjadi berkurang (Sutoyo, T, 2009). Dengan pembuatan sistem klasifikasi mutu greenbean kopi arabika di harapkan mampu meminimalisir kerugian dengan berlanjut second opinion untuk mendapat keuntungan maksimal.

Teknologi pengolahan citra digital dapat digunakan untuk mengklasifikasikan mutu greenbean kopi arabika yang sesuai dengan Standar Nasional Indonesia, terutama dari segi tampilan luar greenbean kopi arabika. Pengolahan citra digital dapat mendeteksi adanya warna, tekstur, juga luas cacat yang terdapat pada greenbean kopi arabika. Deteksi cacat digunakan untuk menghitung luas kecacatan pada greenbean kopi arabika. Fiturfitur citra tersebut kemudian digunakan untuk proses klasifikasi menjadi 4 kelas mutu yaitu kelas arabika lanang utuh, kelas arabika lanang pecah, kelas arabika biasa utuh, dan arabika biasa pecah. Dengan pemanfaatan teknologi tersebut diharapkan konsumen 
maupun produsen dapat dengan mudah mengklasifikasikan mutu greenbean kopi arabika tersebut.

\section{TINJAUAN PUSTAKA}

Klasifikasi yang digunakan dalam sistem ini menggunakan metode $K N N$ (K-Nearest Neighbour) merupakan metode mengklasifikasikan suatu objek dengan mempertimbangkan kelas terdekat dari objek tersebut. $K-N N$ adalah metode berbasis $N N$ (Neural Network) yang paling tua dan paling populer (Dahril, 2014). Metode ini diharapkan mampu mengklasifikasikan greenbean kopi arabika berdasarkan fitur yang di dapat dari citra greenbean kopi.

Pada penelitian (Syahputra, Arnia, \& Munadi, 2019) tentang hasil karakterisasi kematangan buah kopi arabika menggunakan dua fitur warna citra, yaitu histogram dan momen warna. Karakterisasi kematangan dibagi menjadi 4 kelompok yaitu hijau untuk kopi muda, hijau kekuningan untuk kopi setengah masak, merah untuk kopi masak, dan merah tua untuk kopi tua. Hasil penelitian menggunakan 200 citra kopi menunjukkan bahwa nilai statistik dari histogram warna lebih menggambarkan karakter kematangan buah kopi, dibandingkan dengan momen warna. Nilai kurtosis dari histogram hue memiliki nilai berbeda untuk setiap kategori kematangan buah kopi. Kopi muda memiliki nilai kurtosis 17.2-28.3, kopi setengah masak 29,2-31.4, kopi masak 32,7-83,5 dan kopi tua lebih dari 84,2.

Dahril (2014) melakukan penelitian merancang suatu aplikasi yang dapat mengetahui informasi perkiraan cuaca yang terjadi, khususnya daerah Riau. Aplikasi ini dibuat dengan konsep client-server. Metode yang digunakan untuk prediksi cuaca adalah metode Moving Average dan $k$-Nearest Neighbor.

Nasution \& Andayani (2017) melakukan penelitian menggunakan pemrosesan gambar (image processing) untuk mengenali tingkat panggang biji kopi digital dan mengklasifikasikan dengan jaringan saraf tiruan metode backpropagation. Hasil penelitian menunjukkan bahwa metode yang diusulkan mampu mengidentifikasi tingkat panggang biji kopi dengan akurasi $97,5 \%$.

Sari (2004) melakukan penelitian pengolahan citra digital digunakan untuk pengenalan biji kopi utuh, biji kopi pecah, biji kopi berlubang dan benda asing. Pada penelitian tersebut diambil nilai numerik parameter panjang, lebar maksimum, lebar minimum, selisih lebar, roundness, luas dan keliling. Parameter tersebut digunakan sebagai input untuk logika fuzzy. Logika fuzzy digunakan untuk membedakan biji kopi utuh, biji kopi pecah, biji kopi berlubang, dan benda asing. Kemudian diolah menggunakan bahasa pemrograman Visual Basic 6.0 sehingga mendapatkan output komposisi biji kopi utuh, pecah, berlubang dan benda asing.

Ulum, Nasrul. Prismana,I Gusti Lanang Putra Eka. Firdaus (2018) melakukan penelitian tentang identifikasi jenis biji kopi dengan menggunakan metode klasifikasi city block distance. Hasil dari penelitian ini adalah sebuah program yang digunakan untuk mengidentifikasi biji kopi. Dari hasil pengujian bahwa program identifikasi ini menunjukkan akurasi yang tinggi yaitu $77,6 \%$ pada perhitungan jarak Lorentzian ukuran citra $75 \times 75$ dengan 180 data pelatihan dan 45 data uji. Untuk perhitungan jarak Sorensen menunjukkan hasil akurasi sebesar $67,1 \%$ ukuran citra $75 \times 75$ dengan 180 data pelatihan dan 45 data uji.

\section{METODE PENELITIAN}

\subsection{Tempat Penelitian}

Penelitian ini menggunakan greenbean kopi arabika dari temanggung yang sudah dilabeli berdasarkan standarisasi kopi nasional, yaitu greenbean kopi arabika lanang dan 
greenbean kopi arabika biasa. Gambar atau citra dari greenbean kopi sebagai masukan dalam sistem yang akan dibuat. Penelitian ini menentukan citra masukan yang akan menghasilkan suatu keluaran berupa penentuan mutu kopi. Dengan adanya sistem ini, diharapkan dapat memberikan manfaat dalam meneliti dan menentukan kualitas greenbean kopi yang baik. Bahan yang digunakan dalam penelitian adalah 2 greenbean kopi arabika lanang (monokotil) dan biasa (dikotil).

\subsection{Rancangan Secara Keseluruhan}

Pada dasarnya penelitian ini terdiri dari sistem pengambilan citra dan pengolahan citra digital menggunakan komputer. Secara keseluruhan skenario penelitian dilihat pada Gambar 1.

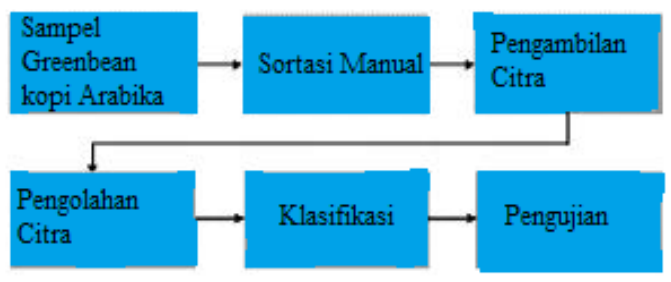

Gambar 1. Skema Penelitian

Tahap pertama penelitian adalah penentuan sampel greenbean kopi arabika. Pada tahap ini diambil sampel greenbean kopi arabika sejumlah 20 greenbean kopi untuk masing-masing kelas. Penelitian ini terdapat 4 kelas greenbean kopi arabika berdasarkan SNI, maka sampel greenbean kopi yang dibutuhkan berjumlah 80 greenbean kopi untuk data training. Kemudian sampel tersebut disortasi secara manual untuk menentukan kelas mutunya.

\subsection{Alur Penelitian}

Penelitian ini bertujuan untuk mengenali mutu greenbean kopi sesuai badan standar nasional. Pengenalan melalui citra atau gambar dilakukan menggunakan sistem yang dirancang oleh peneliti untuk memudahkan dalam pengenalan mutu greenbean kopi arabika. Pada penelitian ini diberikan sebuah input data berupa gambar dan proses output akan menghasilkan nilai akurasi dan mutu greenbean kopi arabika. Metode yang digunakan untuk penelitian ini yaitu $K-N N$ dalam penentuan mutu greenbean kopi arabika yang tepat. Alur penelitian ditunjukan pada gambar 2.

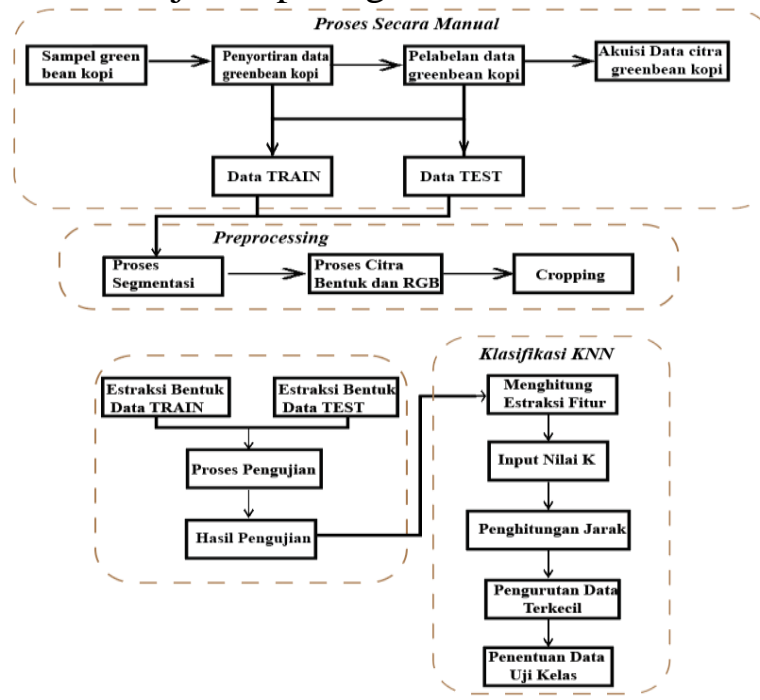

Gambar 2. Alur Penelitian 


\subsection{Perancangan Pengambilan Gambar}

Kotak pengambilan citra dirancang agar proses pengambilan citra dapat dilakukan dengan pencahayaan yang sama, jarak kamera dari objek $19 \mathrm{~cm}$. Rancangan kotak pengambilan citra ini dapat dilihat pada Gambar 3.

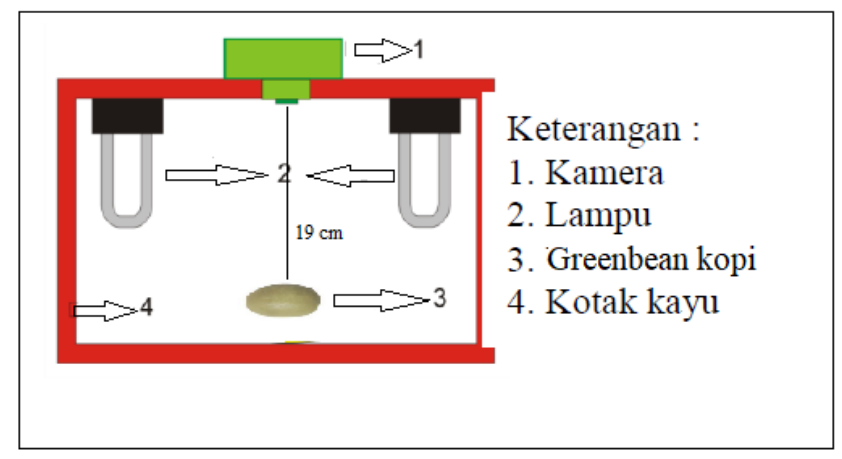

Gambar 3. Rancangan Kotak Pengambilan Citra

\subsection{Algoritma K-Nearest Neighbor $(K-N N)$}

$K$-Nearest Neighbor $(K-N N)$ adalah algoritma supervised learning dimana hasil instan yang baru ditentukan berdasarkan label kelas mayoritas tetangga terdekat. Algoritma klasifikasi K-Nearest Neighbor $(K-N N)$ adalah salah satunya metode paling mudah dimengerti, mudah diimplementasikan, tidak perlu memperkirakan parameter, dan sedikit pelatihan (Duan, 2018). Salah satu penghitungan kedekatan jarak tetangga dengan menggunakan Euclidean distance (Fathoni, Zikky, Nurhayati, \& Prasetyaningrum, 2018).Jarak Euclidean adalah ukuran untuk menemukan jarak antara dua titik. Dalam koordinat Cartesian, jika dan dua titik di ruang-Euclidean, maka jarak (d) dari atau dari ke ditentukan oleh teori Pythagoras (Md Isa, Amir, Ilyas, \& Razalli, 2017)

\section{HASIL DAN PEMBAHASAN}

\subsection{Akuisi Data Ekstraksi Bentuk}

Ektraksi ciri bentuk dilakukan dari rasio perimeter, rasio kebulatan, rasio kerampingan, luas dan juga keliling digunakan untuk mengklasifikasikan greenbean kopi kedalam 4 kelas yaitu greenbean kopi arabika lanang utuh, arabika lanang pecah, arabika biasa utuh, dan arabika biasa pecah. Citra greenbean kopi arabika yang di gunakan sebagai data penelitian ini dapat dilihat pada Gambar 4.

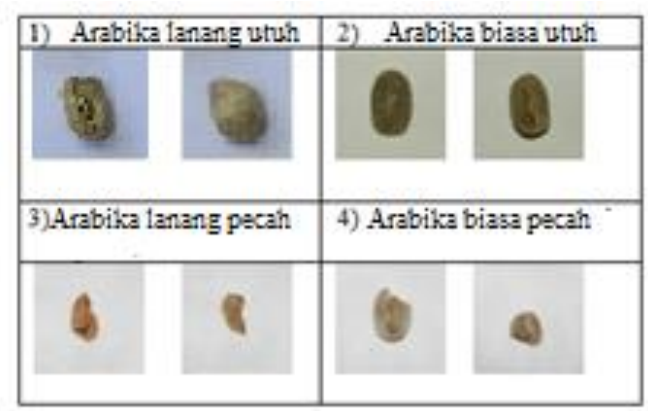

Gambar 4. Hasil Akuisi Greenbean Kopi Arabika

Setelah di ketahui hasil akuisi pada greenbean kopi arabika, dan sistem telah berhasil mengekstraksi fitur dengan hasil yang ditunjukan pada Tabel 1. 
Tabel 1 Hasil Ekstraksi Fitur Greenbean Kopi

\begin{tabular}{|l|c|c|c|c|c|}
\hline \multicolumn{1}{|c|}{ Kelas } & $\begin{array}{c}\text { Rasio } \\
\text { Perimeter }\end{array}$ & $\begin{array}{c}\text { Rasio } \\
\text { Kerampingan }\end{array}$ & $\begin{array}{c}\text { Rasio } \\
\text { Kebulatan }\end{array}$ & Luas & Keliling \\
\hline Arabika Lanang & $\begin{array}{c}0.582 \text { hingga } \\
1.687\end{array}$ & $\begin{array}{c}1.4325 \text { hingga } \\
1.998\end{array}$ & $\begin{array}{c}84.85 \text { hingga } \\
100\end{array}$ & $\begin{array}{c}33 \text { hingga } \\
225\end{array}$ & $\begin{array}{c}19 \text { hingga } \\
54\end{array}$ \\
\hline $\begin{array}{l}\text { Arabika Lanang } \\
\text { Pecah }\end{array}$ & $\begin{array}{c}0.5 \text { hingga } \\
2.229\end{array}$ & $\begin{array}{c}1.4128 \text { hingga } \\
2.1\end{array}$ & $\begin{array}{c}44.39 \text { hingga } \\
100\end{array}$ & $\begin{array}{c}17 \text { hingga } \\
94\end{array}$ & $\begin{array}{c}17 \text { hingga } \\
39\end{array}$ \\
\hline $\begin{array}{l}\text { Arabika Biasa } \\
0.590 \text { hingga } \\
1.833\end{array}$ & $\begin{array}{c}1.4375 \text { hingga } \\
2.0588\end{array}$ & $\begin{array}{c}48.18 \text { hingga } \\
100\end{array}$ & $\begin{array}{c}35 \text { hingga } \\
233\end{array}$ & $\begin{array}{c}22 \text { hingga } \\
58\end{array}$ \\
\hline $\begin{array}{l}\text { Arabika Biasa } \\
\text { Pecah }\end{array}$ & $\begin{array}{c}0.417 \text { hingga } \\
2.333\end{array}$ & $\begin{array}{c}1.3846 \text { hingga } \\
2.2\end{array}$ & $\begin{array}{c}40.87 \text { hingga } \\
100\end{array}$ & $\begin{array}{c}16 \text { hingga } \\
99\end{array}$ & $\begin{array}{c}17 \text { hingga } \\
43\end{array}$ \\
\hline
\end{tabular}

Peneliti melakukan pengujian pada setiap fitur ciri morfologi untuk menemukan akurasi fitur ciri bentuk mana yang lebih baik dalam mengklasifikasikan greenbean kopi berdasarkan jenis kopi arabika lanang dan biasa pada keutuhan bentuknya.

\subsection{Proses Pengujian Klasifikasi}

Peneliti melakukan pengujian pada setiap fitur ciri morfologi untuk menemukan akurasi fitur ciri mana yang lebih baik dalam mengklasifikasikan greenbean kopi berdasarkan jenis dan keutuhan bentuknya. Sebanyak 80 data training dan 40 data uji.

Tabel 2 Hasil Akurasi Rasio Perimeter

\begin{tabular}{|c|c|c|c|c|c|}
\hline \multirow[b]{2}{*}{$\mathbf{K}$} & \multicolumn{4}{|c|}{ Nilai Akurasi (\%) } & \multirow[b]{2}{*}{ Rata-rata } \\
\hline & $\begin{array}{c}\text { Arabika } \\
\text { Biasa Utuh }\end{array}$ & $\begin{array}{c}\text { Arabika Biasa } \\
\text { Pecah }\end{array}$ & $\begin{array}{c}\text { Arabika } \\
\text { Lanang Utuh }\end{array}$ & $\begin{array}{c}\text { Arabika lanang } \\
\text { Pecah }\end{array}$ & \\
\hline 3 & $50 \%$ & $33 \%$ & $51 \%$ & $36.4 \%$ & $42 \%$ \\
\hline 6 & $33,3 \%$ & $27.5 \%$ & $66 \%$ & $64 \%$ & $47.7 \%$ \\
\hline 9 & $20 \%$ & $22.2 \%$ & $38 \%$ & $45.5 \%$ & $31.4 \%$ \\
\hline 12 & $30 \%$ & $44.4 \%$ & $32 \%$ & $38.1 \%$ & $36.1 \%$ \\
\hline 15 & $30 \%$ & $33.33 \%$ & $33.33 \%$ & $21.4 \%$ & $29.5 \%$ \\
\hline
\end{tabular}

Pada penelitian yang dilakukan, untuk fitur rasio perimeter adalah perbandingan perimeter dengan jumlah lebar dan tinggi pada objek. akurasi tertinggi pada fitur rasio perimeter yaitu hanya $47,7 \%$, cukup baik dalam mendeteksi greenbean arabika lanang utuh dan arabika lanang pecah namun fitur ini lemah dalam membedakan greenbean arabika biasa utuh dan arabika biasa pecah.

Tabel 3 Hasil Akurasi Kerampingan

\begin{tabular}{|c|c|c|c|c|c|}
\hline \multirow[b]{2}{*}{$\mathbf{K}$} & \multicolumn{4}{|c|}{ Nilai Akurasi (\%) } & \multirow[b]{2}{*}{ Rata-rata } \\
\hline & $\begin{array}{c}\text { Arabika } \\
\text { Biasa Utuh }\end{array}$ & $\begin{array}{c}\text { Arabika Biasa } \\
\text { Pecah }\end{array}$ & $\begin{array}{c}\text { Arabika } \\
\text { Lanang Utuh }\end{array}$ & $\begin{array}{c}\text { Arabika } \\
\text { Lanang Pecah }\end{array}$ & \\
\hline 3 & $60 \%$ & $60 \%$ & $72.7 \%$ & $66.7 \%$ & $64.8 \%$ \\
\hline 6 & $70 \%$ & $22 \%$ & $54.5 \%$ & $55.5 \%$ & $50.5 \%$ \\
\hline 9 & $70 \%$ & $68 \%$ & $69.1 \%$ & $44.4 \%$ & $62.8 \%$ \\
\hline 12 & $40 \%$ & $70 \%$ & $31.2 \%$ & $37.5 \%$ & $44.6 \%$ \\
\hline 15 & $60 \%$ & $60 \%$ & $27.3 \%$ & $10 \%$ & $39.2 \%$ \\
\hline
\end{tabular}


Penelitian yang dilakukan pada fitur kerampingan akurasi tertinggi pada K3 yaitu dengan nilai akurasi $64.8 \%$, fitur ini bisa mendeteksi semua kelas greenbean kopi dengan akurasi pada arabika biasa utuh dan pecah sebesar $70 \%$.

Tabel 4 Hasil Akurasi Fitur Rasio Kebulatan

\begin{tabular}{|l|l|l|l|l|l|}
\hline \multirow{2}{*}{ K } & \multicolumn{4}{|c|}{ Nilai Akurasi (\%) } & \multirow{2}{*}{ Rata-rata } \\
\cline { 2 - 5 } & $\begin{array}{c}\text { Arabika Biasa } \\
\text { Utuh }\end{array}$ & $\begin{array}{c}\text { Arabika } \\
\text { Biasa Pecah }\end{array}$ & $\begin{array}{c}\text { Arabika } \\
\text { Lanang Utuh }\end{array}$ & $\begin{array}{c}\text { Arabika } \\
\text { Lanang Pecah }\end{array}$ & \\
\hline 3 & $50 \%$ & $66,7 \%$ & $21 \%$ & $27,2 \%$ & $41.2 \%$ \\
\hline 6 & $60 \%$ & $66,7 \%$ & $18 \%$ & $36,4 \%$ & $45,2 \%$ \\
\hline 9 & $70 \%$ & $66,7 \%$ & $26 \%$ & $12 \%$ & $43.6 \%$ \\
\hline 12 & $50 \%$ & $33,3 \%$ & $34 \%$ & $36.4 \%$ & $38,4 \%$ \\
\hline 15 & $70 \%$ & $33,3 \%$ & $36 \%$ & $41 \%$ & $45 \%$ \\
\hline
\end{tabular}

Pada fitur rasio kebulatan akurasi tertinggi hanya mencapai $45,2 \%$, cukup baik dalam mendeteksi greenbean kopi arabika biasa utuh dan arabika biasa pecah kelemahan dalam fitur ini sulit membedakan greenbean kopi arabika lanang utuh dan greenbean arabika lanang pecah. Jumlah piksel yang digunakan untuk menyusun suatu citra mempengaruhi kualitas citra, semakin banyak piksel pada citra maka akan semakin detail (Kadir \& Susanto, 2013).

Tabel 5 Hasil Akurasi Fitur Luas Area

\begin{tabular}{|c|c|c|c|c|c|}
\hline \multirow[b]{2}{*}{$\mathbf{K}$} & \multicolumn{4}{|c|}{ Nilai Akurasi (\%) } & \multirow[t]{2}{*}{ Rata-rata } \\
\hline & $\begin{array}{c}\text { Arabika } \\
\text { Biasa Utuh }\end{array}$ & $\begin{array}{c}\text { Arabika Biasa } \\
\text { Pecah }\end{array}$ & $\begin{array}{c}\text { Arabika Lanang } \\
\text { Utuh }\end{array}$ & $\begin{array}{c}\text { Arabika Lanang } \\
\text { Pecah }\end{array}$ & \\
\hline 3 & $88 \%$ & $44,4 \%$ & $66 \%$ & $61.4 \%$ & $64,9 \%$ \\
\hline 6 & $90 \%$ & $88,9 \%$ & $91 \%$ & $9.5 \%$ & $69,8 \%$ \\
\hline 9 & $86 \%$ & $55,6 \%$ & $84 \%$ & $19.4 \%$ & $61 \%$ \\
\hline 12 & $92 \%$ & $44,4 \%$ & $97 \%$ & $41.4 \%$ & $68,7 \%$ \\
\hline 15 & $90 \%$ & $44,4 \%$ & $88 \%$ & $21.7 \%$ & $61 \%$ \\
\hline
\end{tabular}

Fitur luas area ini mampu mendeteksi arabika lanang utuh mecapai 97\% benar. Dan fitur ini mampu mendeteksi semua kelas greenbean kopi dengan akurasi rata-rata pada greenbean arabika sebesar 69,8\%.

Tabel 6 Hasil Akurasi Fitur Keliling

\begin{tabular}{|c|c|c|c|c|c|}
\hline \multirow[b]{2}{*}{$\mathbf{K}$} & \multicolumn{4}{|c|}{ Nilai Akurasi (\%) } & \multirow[b]{2}{*}{ Rata-rata } \\
\hline & $\begin{array}{c}\text { Arabika } \\
\text { Biasa Utuh }\end{array}$ & $\begin{array}{c}\text { Arabika } \\
\text { Biasa Pecah }\end{array}$ & $\begin{array}{c}\text { Arabika } \\
\text { Lanang Utuh }\end{array}$ & $\begin{array}{c}\text { Arabika } \\
\text { Lanang Pecah } \\
\end{array}$ & \\
\hline 3 & $50 \%$ & $44,4 \%$ & $62 \%$ & $55,3 \%$ & $52,9 \%$ \\
\hline 6 & $90 \%$ & $11,1 \%$ & $72 \%$ & $38,1 \%$ & $52,8 \%$ \\
\hline 9 & $90 \%$ & $22,2 \%$ & $43 \%$ & $38,1 \%$ & $45,5 \%$ \\
\hline 12 & $90 \%$ & $22,2 \%$ & $62 \%$ & $37,2 \%$ & $52,8 \%$ \\
\hline 15 & $80 \%$ & $11,1 \%$ & $62 \%$ & $47,4 \%$ & $50,1 \%$ \\
\hline
\end{tabular}

Pada tahap pengujian menggunakan fitur ciri yaitu keliling. Dari 40 data uji fitur ini dapat mendeteksi 52,9\% dengan benar. Akurasi terbaik dalam mendeteksi greenbean Arabika biasa utuh yaitu mencapai $90 \%$. 
Tabel 7 Hasil Akurasi Klasifikasi $K-N N$

\begin{tabular}{|c|c|c|c|c|c|}
\hline \multirow{2}{*}{ K } & \multicolumn{4}{|c|}{ Nilai Akurasi (\%) } & \multirow{2}{*}{ Rata-rata } \\
\cline { 2 - 5 } & $\begin{array}{c}\text { Arabika } \\
\text { Biasa Utuh }\end{array}$ & $\begin{array}{c}\text { Arabika } \\
\text { Biasa Pecah }\end{array}$ & $\begin{array}{c}\text { Arabika } \\
\text { Lanang Utuh }\end{array}$ & $\begin{array}{c}\text { Arabika } \\
\text { Lanang Pecah }\end{array}$ & \\
\hline 3 & $90 \%$ & $55,5 \%$ & $69 \%$ & $39,4 \%$ & $63,5 \%$ \\
\hline 6 & $90 \%$ & $33,8 \%$ & $87 \%$ & $27.7 \%$ & $59,6 \%$ \\
\hline 9 & $90 \%$ & $21,4 \%$ & $97 \%$ & $38.1 \%$ & $61,6 \%$ \\
\hline 12 & $90 \%$ & $24,2 \%$ & $84 \%$ & $47.5 \%$ & $61.4 \%$ \\
\hline 15 & $90 \%$ & $11,1 \%$ & $76 \%$ & $48.7 \%$ & $56,5 \%$ \\
\hline
\end{tabular}

Hasil dari klasifikasi menggunakan semua fitur yaitu, rasio perimeter, kerampingan, rasio kebulatan, luas area dan keliling memperoleh akurasi sebesar 63,5\%. Sistem dapat mengenali dengan baik greenbean kopi arabika lanang utuh yaitu akurasi 97\%. Berbeda dengan penelitian sebelumnya menggunakan 3 fitur morfologi rasio kebulatam, luas area dan keliling memperoleh akurasi 82,56\% dengan akurasi Robusta 78,46\% (Arboleda, Fajardo, \& Medina, 2018).

\section{KESIMPULAN DAN SARAN}

\subsection{Kesimpulan}

Berdasarkan dari hasil penelitian dengan judul metode klasifikasi mutu greenbean kopi arabika lanang dan biasa menggunakan $K-N N$ Berdasarkan Bentuk maka dapat diambil kesimpulan.

1. Klasifikasi mutu greenbean kopi dengan 4 ekstraksi ciri menggunakan $K$-NN memperoleh akurasi sebesar $63,5 \%$ dengan nilai $\mathrm{K} 3$.

2. Fitur terbaik dalam mendeteksi greenbean kopi adalah fitur luas area dengan memperoleh akurasi 69,8\%, fitur ini juga mampu mendeteksi lebih baik greenbean kopi yang utuh dan tidak utuh berdasarkan jenis greenbean kopinya dibandingkan dengan 4 fitur lainnya.

3. Fitur yang diekstraks untuk klasifikasi greenbean kopi arabika adalah perimeter, rasio kebulatan, rasio kerampingan, luas dan rasio keliling.

\subsection{Saran}

Mengenai klasifikasi mutu greenbean kopi, maka penulis memberikan saran sebagai berikut:

1. Perlu ditambahkan fitur dalam memperbaiki noise menggunakan satu metode operasi morfologi closing, pada sistem ini hanya mampu mendeteksi noise yang berada ditengah objek. Disarankan untuk menambahkan proses perbaikan citra lainya.

2. Perlu adanya penambahan fitur lain dalam proses klasifikasi agar perbedaan antara greenbean kopi arabika lanang dan biasa lebih signifikan.

3. Penelitian selanjutnya dapat mencoba dengan metode yang lain untuk mendapatkan proses klasifikasi yang lebih akurat dan efisien.

\section{DAFTAR PUSTAKA}

Badan Standarisasi Nasional (BSN) SNI 01-2907:2008 Tentang Biji kopi

Arboleda, E. R., Fajardo, A. C., \& Medina, R. P. (2018). Classification of coffee bean species using image processing, artificial neural network and $\mathrm{K}$ nearest neighbors. 2018 IEEE International Conference on Innovative Research and Development, ICIRD 2018. https://doi.org/10.1109/ICIRD.2018.

Dahril, M. (2014). Aplikasi Prakiraan Cuaca Se-Riau Berbasis Android Menggunakan Metode Moving Average Dan K-Nearest Neighbor. Aksara Komputer Terapan. 
Pekanbaru, Politeknik Caltex Riau.

Duan, Z. (2018). Characters recognition of binary image using KNN, "In Proceedings of the 4th International Conference on Virtual Reality (ICVR), pp:116-118.

Fathoni, K., Zikky, M., Nurhayati, A. S., \& Prasetyaningrum, I. (2018). Application of KNearest Neighbor Algorithm for Puzzle Game of Human Body's System Learning on Virtual Mannequin. Proceedings - 2018 International Conference on Applied Science and Technology, ICAST 2018.

Kadir, A., \& Susanto, A. (2013). Pengantar Pengolahan Citra. Teori Dan Aplikasi Pengolahan Citra.

Md Isa, N. E. Z., Amir, A., Ilyas, M. Z., \& Razalli, M. S. (2017). The Performance Analysis of K-Nearest Neighbors (K-NN) Algorithm for Motor Imagery Classification Based on EEG Signal. MATEC Web of Conferences. https://doi.org/10.1051/matecconf/201714001024

Nasution, T. H., \& Andayani, U. (2017). Recognition of roasted coffee bean levels using image processing and neural network. IOP Conference Series: Materials Science and Engineering. https://doi.org/10.1088/1757-899X/180/1/012059

Sari, N. (2004). Pendugaan Biji Kopi Utuh, Bjji Kopi Pecah, Biji Kopi Berlubang dan Benda Asing Untuk Evaluasi Mutu Kopi Dencan Pengolahan Citra dan Metode Fuzzy. Skripsi Jurusan Teknik Pertanian Fakultas Pertanian IPB, Bogor.

Sutoyo, T, dkk. (2009). Teori Pengolahan Citra Digital. Andi, Yogyakarta hal 9 - 27.

Syahputra, H., Arnia, F., \& Munadi, K. (2019). Karakterisasi Kematangan Buah Kopi

Berdasarkan Warna Kulit Kopi Menggunakan Histogram dan Momen Warna. Jurnal Nasional Teknik Elektro. Vol. 8, No. 1, Maret p-ISSN: 2302-2949, e-ISSN: $2407-7267$

Ulum, Nasrul. Prismana,I Gusti Lanang Putra Eka. Firdaus, R. A. J. (2018). Identifikasi Jenis Biji Kopi Menggunakan Citra Digital Dengan Metode Klasifikasi City Block Distance. Inovate. Volume 03 Nomor 01, 30-37 